\title{
Vaccination accelerates hepatic erythroblastosis induced by blood-stage malaria
}

\author{
Denis Delic ${ }^{1,2^{*}}$ (D, Frank Wunderlich', Saleh Al-Quraishy ${ }^{3}$, Abdel-Azeem S. Abdel-Baki ${ }^{3,4}$, Mohamed A. Dkhil2,5 \\ and Marcos J. Araúzo-Bravo 6,7
}

\begin{abstract}
Background: Vaccination induces survival of otherwise lethal blood-stage infections of the experimental malaria Plasmodium chabaudi. Blood-stage malaria induces extramedullary erythropoiesis in the liver. This study investigates how vaccination affects the course of malaria-induced expression of erythrocytic genes in the liver.

Methods: Female Balb/c mice were vaccinated at week 3 and week 1 before challenging with $10^{6}$ P. chabaudi-parasitized erythrocytes. The non-infectious vaccine consisted of erythrocyte ghosts isolated from P. chabaudi-infected erythrocytes. Gene expression microarrays and quantitative real-time PCR were used to compare mRNA expression of different erythrocytic genes in the liver of vaccination-protected and non-protected mice during infections on days 0 , $1,4,8$, and 11 p.i.

Results: Global transcriptomics analyses reveal vaccination-induced modifications of malaria-induced increases in hepatic gene expression on days 4 and 11 p.i. On these days, vaccination also alters hepatic expression of the erythropoiesis-involved genes Ermap, Kel, Rhd, Rhag, Slc4a1, Gypa, Add2, Ank1, Epb4.1, Epb4.2, Epb4.9, Spta1, Sptb, Tmod1, Ahsp, Acyp1, Gata1, Gfilb, Tal1, KIf1, Epor, and Cldn13. In vaccination-protected mice, expression of these genes, except Epb4.1, is significantly higher on day 4 p.i. than in un-protected non-vaccinated mice, reaches maximal expression at peak parasitaemia on day 8 p.i., and is slowed down or even decreased towards the end of crisis phase on day 11 p.i.. After day 1 p.i., Epor expression takes about the same course as that of the other erythroid genes. Hepatic expression of Epo, however, is delayed in both vaccinated and non-vaccinated mice for the first 4 days p.i. and is maximal at significantly higher levels in vaccinated mice on day 8 p.i., before declining towards the end of crisis phase on day 11 p.i.

Conclusion: The present data indicate that vaccination accelerates malaria-induced erythroblastosis in the liver for 1-2 days. This may contribute to earlier replenishment of peripheral red blood cells by liver-derived reticulocytes, which may favour final survival of otherwise lethal blood-stage malaria, since reticulocytes are not preferred as host cells by P. chabaudi.
\end{abstract}

Keywords: Liver, Blood-stage malaria, Plasmodium chabaudi, Protective vaccination, Extramedullary erythropoiesis

\section{Background}

Malaria has caused about 219 million cases and about 435,000 deaths globally in 2017, with about 266,000 deaths in children aged under 5 years [1]. Currently, promising vaccine candidates are tested, but an effective

\footnotetext{
*Correspondence: denis.delic@boehringer-ingelheim.com

2 Boehringer Ingelheim Pharma, Biberach, Germany

Full list of author information is available at the end of the article
}

anti-malarial vaccine is not yet commercially available [2-4].

The malaria-causing agents are parasitic protozoans of the genus Plasmodium, whose blood-stages, developing and multiplicating within host erythrocytes, exclusively cause morbidity and mortality of malaria [3]. The deadliest human malaria species is Plasmodium falciparum causing about $99 \%$ of global malaria-related deaths in humans [1]. Plasmodium falciparum shares several 
characteristics with Plasmodium chabaudi in mice which is, therefore, widely used as an appropriate experimental system to study host defense mechanisms against bloodstage malaria $[5,6]$. The $P$. chabaudi model is also appropriate to study effects of vaccination on the outcome of blood-stage malaria. Using an experimental non-infectious vaccine, survival of mice can be raised from $0 \%$ to over $80 \%[7,8]$. This vaccine induces a healing course of otherwise lethal infections. For instance, primary infections with $10^{6} \mathrm{P}$. chabaudi-parasitized erythrocytes take a similar course in terms of parasitaemia in vaccinated and non-vaccinated mice of the inbred mouse strain Balb/c [8]. The prepatent phase lasts for about 3 days, before the patent period begins on day 4 post infectionem (p.i.), characterized by the appearance of parasitized erythrocytes in the peripheral blood. The parasitaemias vary among infected mice between 1-5\% without any difference between vaccinated and non-vaccinated mice. Maximum parasitaemia is reached on day 8 p.i. with about $60 \%$ parasitaemia in non-vaccinated mice, whereas it is reduced to about $40 \%$ in vaccinated mice. Peak parasitaemia is followed by the crisis phase characterized by dramatically declining parasitaemias to $5-1 \%$ within 3-4 days. All non-vaccinated mice succumb to infection during crisis, whereas over $80 \%$ of the vaccinated mice survive the infections [8].

The massive clearance of $P$. chabaudi-parasitized erythrocytes from circulation during crisis is ascribed to the spleen, which is widely considered as the exclusive effector organ against blood-stage malaria $[9,10]$. Indeed, the spleen is thought of using the same mechanisms for eliminating malaria-parasitized erythrocytes in its red pulp, by which it normally removes senescent erythrocytes from circulation. Moreover, the liver is increasingly recognized as an effector organ against blood-stage malaria [11] due to its intrinsic immune system, its specific iron disposal system, and its capability to remove senescent and other aberrant erythrocytes including $P$. chabaudiparasitized erythrocytes [11-16].

In $P$. chabaudi infections, the dramatic low levels of peripheral erythrocytes towards the end of crisis occur, though erythropoiesis is concomitantly active evidenced as increasing levels of peripheral reticulocytes [8]. Erythropoiesis is a highly complex process proceeding from the commitment of a haematopoietic stem cell to the megakaryocyte-erythroid lineage, which generates the primitive progenitors of the erythrocyte lineage, i.e., the slowly proliferating burst-forming unit-erythroid cells followed by the rapidly expanding colony-forming unit-erythroid (CFU-e) cells. These in turn are the precursors for the nucleated pro-erythroblasts and erythroblasts [17-19], which are arranged in erythroblastic islands organized around a central macrophage $[20,21]$. Erythroblasts denucleate to reticulocytes which terminally differentiate to erythrocytes $[20,22]$. Erythropoietin (EPO) and erythropoietin receptor (EPOR), respectively, play a critical role in erythropoiesis, in particular during erythroblastosis. EPOR is constitutively expressed on CFU-e and erythroblasts [23, 24]. EPO-sensitive erythropoiesis is obviously also critical for the outcome of $P$. chabaudi blood-stage malaria $[25,26]$. In particular, EPO-induced proliferation of erythroid precursors has been described to be suppressed by parasite factors thus causing severe anaemia and exacerbating effects on the final outcome of $P$. chabaudi infections [27].

Erythropoiesis takes place in the bone marrow [20, 21]. Evidence, however, is increasing that, under specific stress situations, erythropoiesis can also take place outside the bone marrow. This stress or extramedullary erythropoiesis has been reported to occur in several organs, particularly in the spleen, of mice and even humans [20, 28-31]. Previously, the spleen was found to be a site of increased erythropoiesis in $P$. chabaudi-resistant C57BL/6 mice [32]. Thereafter, the liver was also found to be a site of malaria-induced erythropoiesis. Thus, blood-stage infections with the non-lethal Plasmodium yoelii 17XL in C57BL/6 mice were reported to induce large cell clusters containing TER $119^{+}$nucleated reticulocytes in the parenchymal space of the liver [33, 34]. This aspect has been neglected until recently when several erythrocytic genes were detected by transcriptomics screening analyses to be expressed in the liver of mice infected with $P$. chabaudi $[35,36]$. At present, however, there is only poor information available on the dynamics of stress-induced extramedullary erythropoiesis in general and, in particular, on the dynamics of malaria-induced extramedullary erythropoiesis in the liver at the gene expression level. To get a better understanding of extramedullary erythropoiesis in the liver induced by blood-stage malaria and, particularly, its modulation by vaccination, this study comparatively analyses the time-course of expression of a series of erythrocytic genes in the liver during primary blood-stage infections of $P$. chabaudi taking a lethal outcome in non-vaccinated mice and, in parallel, during healing infections in vaccination-protected surviving mice. These data are discussed with respect to $P$. chabaudi-induced changes in peripheral blood previously analysed under identical experimental conditions as used here [8].

\section{Methods}

Mice

Experiments were performed with female Balb/c mice aged 10-12 weeks, which were delivered from the central animal facility of the University of Düsseldorf, where mice were bred under specified pathogen-free conditions. 
During infection experiments, mice were housed in plastic cages and received a standard diet (Woehrlin, Bad Salzuflen, Germany) and water ad libitum.

\section{Protective vaccination}

Vaccination was performed under identical experimental conditions as described previously [8]. The non-infectious vaccine, consisting of erythrocyte ghosts isolated from $P$. chabaudi-parasitized erythrocytes, was prepared as detailed previously $[7,8,37]$. These membrane ghosts were previously characterized to contain parasite-synthesized proteins [38,39]. Approximately $10^{6}$ ghosts suspended in $100 \mu \mathrm{l}$ Freund's complete adjuvant (FCA) were subcutaneously injected at weeks 3 and 1 before infection with $P$. chabaudi blood-stage malaria. In parallel, only FCA was injected in control mice.

\section{Blood-stage malaria of $P$. chabaudi}

Plasmodium chabaudi infections were maintained in outbred mice by weekly passages of infected blood under sterile conditions. The non-clonal line of P. chabaudi [40], resembles $P$. chabaudi AS clone in terms of restriction fragment length polymorphism as well as dihydrofolate reductase and cysteine protease sequence identities [41]. Moreover, the used line of $P$. chabaudi is self-healing as the AS clone, which is under control of genes of the $\mathrm{H}-2$ complex and the non-H-2 background as well as sex and sex hormones of the infected mouse strain [42]. The $\mathrm{Balb} / \mathrm{c}$ mice were infected with $10^{6} \mathrm{P}$. chabaudi-infected erythrocytes. Parasitaemia was evaluated in Giemsastained smears from tail blood and erythrocytes were counted in a Neubauer chamber as described previously [8]. Both groups of vaccinated and non-vaccinated mice contained 4 'control' mice, which were not sacrificed for liver sampling. All 4 mice in the non-vaccinated group succumbed to infection during crisis. In the vaccinated group, however, only 1 mouse succumbed to infection during crisis, whereas 3 mice survived the infection for at least 3 weeks, in accordance with previous results [8].

\section{Liver sampling}

To analyse hepatic gene expression during the course of $P$. chabaudi infections, both vaccinated $(\mathrm{V})$ and nonvaccinated mice $(\mathrm{N})$ were concomitantly infected, and groups of 3 mice were sacrificed at different time points of infections: upon infection on day 0 p.i. (groups Vd0 and $\mathrm{Nd} 0$ ), at early prepatency on day 1 p.i. (groups $\mathrm{Vd} 1$ and $\mathrm{Nd} 1$ ), at early patency on day 4 p.i. (groups $\mathrm{Vd} 4$ and $\mathrm{Nd} 4$ ) when parasitized erythrocytes begin to appear in peripheral blood with parasitaemias varying between $1-5 \%$, at peak parasitaemia on day 8 p.i. (groups Vd8 and $\mathrm{Nd} 8$ ), and towards the end of the crisis phase on day 11 p.i. (groups Vd11 and Nd11) when parasitaemia declined to $5-1 \%$. The course of parasitaemia was previously determined in mice sacrificed in the different groups [43], which corresponded to that in living infected mice under identical experimental conditions [8]. Livers were aseptically removed from sacrificed mice, rapidly frozen in liquid nitrogen and stored at $-80^{\circ} \mathrm{C}$ until use.

\section{RNA isolation}

Frozen livers were individually ground in a mortar under liquid nitrogen. Total RNA was isolated from 'pulverized' aliquots of each individual liver by the standard Trizol protocol (Qiagen, Hilden, Germany), followed by an additional cleaning up with the miRNeasy Kit (Qiagen). The Agilent 2100 Bioanalyser platform (Agilent Technologies) was then used to check integrity and quality of RNA. The RIN values of all 30 liver RNA samples ranged between 8.7 and 9.1 .

\section{Cy3 labelling of RNA}

Each RNA sample (equivalents of $100 \mathrm{ng}$ ) were used to produce Cy3-labeled cRNA using the Agilent Low Input Quick Amp Labeling Kit (Agilent Technologies) according to the manufacturer's protocol. Yields of cRNA and dye-incorporation were determined with the ND-1000 Spectrophotometer (NanoDrop Technologies). The incorporations ranged between 18 and $23 \mathrm{fmol} \mathrm{Cy3/ng}$ cRNA.

\section{Hybridization of Agilent mouse whole genome oligo microarrays}

Agilent's $8 \times 60 \mathrm{~K}$ oligo microarrays (design number 028005) were used, which contained 8 arrays per slide. Each array displayed 39,430 Entrez Gene RNAs. Using the Agilent Gene Expression Hybridization Kit, hybridization was performed according to the Agilent processing protocol (Agilent technologies). Specifically, $600 \mathrm{ng}$ Cy3-labelled fragmented cRNA was hybridized overnight at $65{ }^{\circ} \mathrm{C}$ using Agilent's recommended hybridization chamber and oven. Finally, the microarrays were washed with the Agilent Gene Expression Wash Buffer 1 for $1 \mathrm{~min}$ at room temperature and then with the preheated Agilent Gene Expression Wash Buffer 2 at $37^{\circ} \mathrm{C}$ for $1 \mathrm{~min}$.

\section{Scanning and analyses of microarrays}

Microarrays were scanned with the Agilent's Microarray Scanner System (Agilent Technologies). Microarray image files were processed with the Agilent Feature Extraction Software determining feature intensities (including background substraction), rejecting outliers and calculating statistical confidences of the array spots. All the 30 microarrays were normalized by the quantile method. When required, the expression variance was 
stabilized through the $\log _{2}$ transform. In-home functions developed in Matlab (MathWorks) were used to construct heat maps, the hierarchical clustering dendrograms (calculated using the unweighted pair group method with arithmetic mean and Euclidean distance measure), and the principal component analysis (PCA). The microarray data have been deposited at the NCBI's Gene Expression Omnibus (GEO) database with accession number GSE129133.

\section{Microarray-based analyses of genes involved in erythropoiesis}

The used Agilent's $8 \times 60 \mathrm{~K}$ microarrays contain probes for the following genes: Acyp1 (acylphosphatase 1 erythrocyte isozyme), Add2 (adducin2), Ahsp ( $\alpha$ hemoglobin stabilizing protein), Ank1 (ankyrin1), Cldn13 (claudin13), Epb4.1 (Erythrocyte membrane protein band 4.1), Epb4.2 (Erythrocyte membrane protein 4.2), Epb4.9 (Erythrocyte membrane protein 4.9), Epo (erythropoietin), Epor (erythropoietin receptor), Ermap (erythroblast membrane associated protein), Gata1 (GATA-binding factor 1), Gfilb (growth factor independent $1 B$ transcriptional repressor), Gypa (glycophorin A), Kel (Kell blood group antigen), Klf1 (Krueppel-like factor 1), Rhag (Rh-associated glycoprotein), Rhd (Rh blood group D antigen), Slc4a1 (solute carrier family 4 member $1=$ protein band 3), Spta1 (spectrin $\alpha$ erythrocytic 1), Sptb (Spectrin $\beta$ erythrocytic), Tal1 (T-cell acute lymphocytic leukemia protein 1), and Tmod1 (tropomodulin 1). The expression profiles of these 23 genes were determined from the normalized microarrays prepared from the individual livers of both vaccinated and non-vaccinated mice during infections with $P$. chabaudi on days $0,1,4,8$, and 11 p.i. Gene expression levels, measured as light intensities above the normalization level, were given as mean $\pm \mathrm{SD}$ as a dispersion metric in all figures. T-test was used to determine statistical significance of differences of gene expression levels between vaccinated and non-vaccinated mice both at a given day $p . i$. and during the intervals between the different sampling days $p . i$. The number of '*' marks in the figures that appear over interval lines between sampling points or over the sampling points are the number of zeros after the decimal point of the $p$-values for the statistical significance of the difference in instant of the two series and of the difference between two intervals, respectively.

\section{Quantitative real-time PCR of erythroid genes}

High Capacity cDNA Reverse Transcription Kit (Life Technologies) and TaqMan mRNA assays (Life Technologies) were used to perform reverse transcription of mRNAs coding for the following proteins: RHD (assay ID: Mm00456910_m1), ERMAP (Mm_00469273 $\mathrm{m} 1), \quad$ GATA1 (Mm01352636_m1), SLC4A1
(Mm00441492_m1), CLDN13 (Mm00491038_s1), ADD2 (Mm00478923_m1), ACYP1 (Mm00481325_m1), EPB4.2 (Mm00469111_m1), EPB4.9 (Mm00469121_m1), EPOR (Mm01202755_m1), and EPO (Mm00833882_m1). The TaqMan ${ }^{\circledR}$ gene expression master mix (Life Technologies) was used for PCR reactions according to the instructions given by the manufacturer on a $7900 \mathrm{HT}$ real-time PCR System, as previously described [35]. Raw $\mathrm{Ct}$ values were calculated using the SDS software v.2.4 with GAPDH (Glycerinaldehyd-3-phosphat-Dehydrogenase) for normalization, and the comparative Ct method $\left(2^{-\Delta \Delta \mathrm{Ct}}\right)$ was used to calculate fold change of expression [44]. Statistical significance of corresponding data sets between vaccinated and non-vaccinated mice were analysed with the two-tailed unpaired heteroskedastic Student's T-test $(*=p$-value $<0.05)$.

\section{Results}

Global transcriptomics analyses reveal modifications by vaccination of malaria-induced hepatic gene expression on days 4 and $11 p . i$

The effect of protective vaccination on the time course of erythroid gene expression in the liver induced by $P$. chabaudi blood-stage malaria was analysed using mouse whole genome $8 \times 60 \mathrm{~K}$ oligo microarrays. In toto, 30 microarrays were used for 30 livers prepared from the 10 different groups of vaccination-protected and unprotected non-vaccinated mice at the different phases of infections, i.e., upon infection on day 0 p.i., at early prepatency on day $1 p . i$., at early patency on day $4 p . i$, at peak parasitaemia on day 8 p.i., and towards the end of crisis on day $11 p . i$.

Figure 1a shows the heatmap of gene expression profiles of those probes whose range or variation across all samples were at least 7 in the 10 different groups. In general, there is a good replicability among the three replicates of each analysed condition. The heatmap also shows a gradual change in gene expression across time both in non-vaccinated and vaccinated samples with an abrupt change in gene expression at peak parasitaemia on day $8 p . i$. As the heatmap, the hierarchical clustering of the 30 different individual samples, shown as a dendogram in Fig. 1b, also reveals a good replicability among the three replicates of each analysed condition and the abrupt change in gene expression on day 8 p.i. There are two main branches splitting the samples taken on days 0 , 1 , and 4 p.i. (red branches in Fig. 1b) from the samples taken on days 8 and 11 p.i. (blue branches in Fig. 1b). The principal component analysis (PCA) of gene expression (Fig. 1c) shows that the 1st principal component (PC1) accounts for $40 \%$ of the gene expression variability and the 2 nd PC2 captures $10 \%$ of the variability. The 1st principal axis, that is the most informative, separates between 

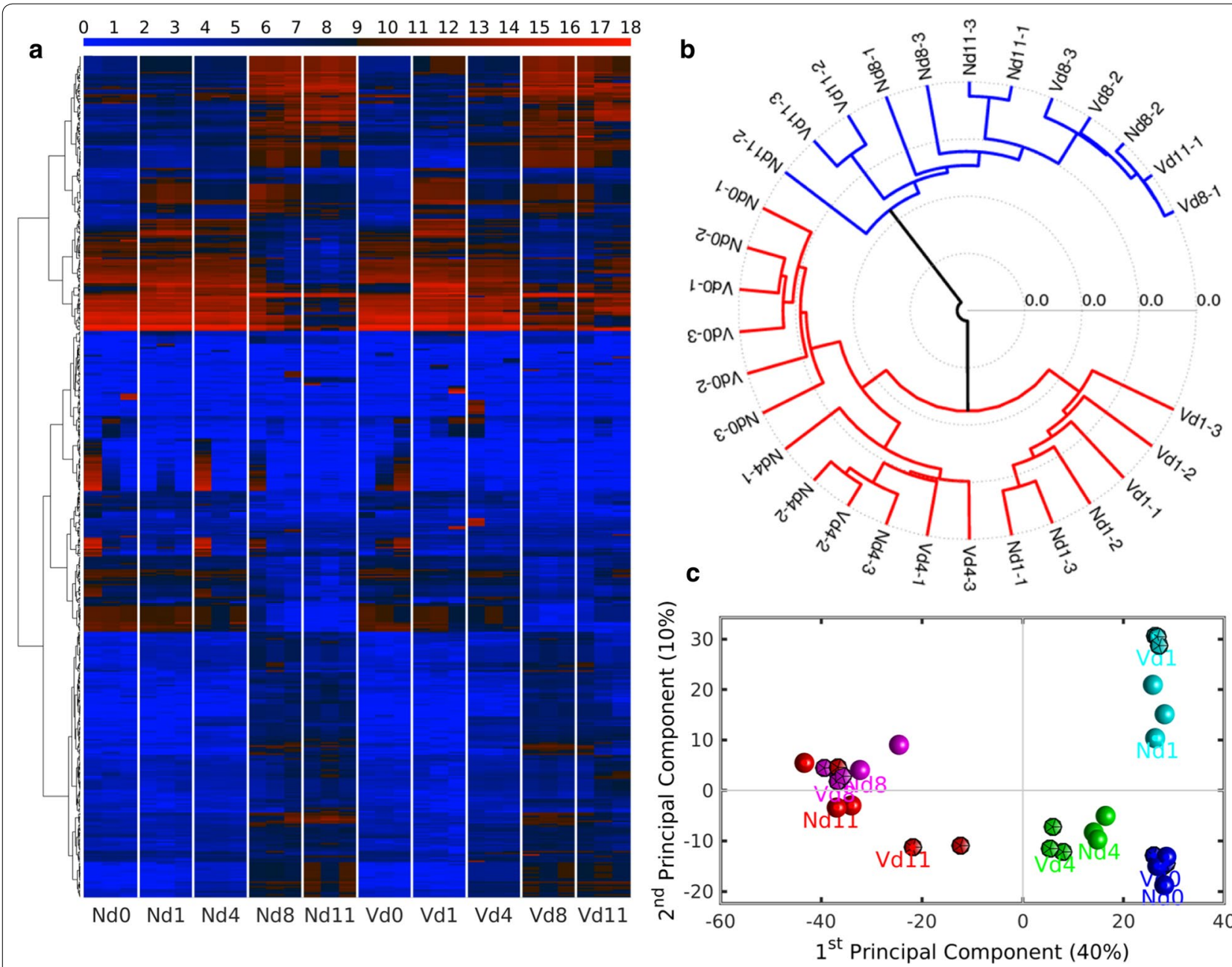

Fig. 1 Global expression profile of mRNAs in the liver of non-vaccinated $(\mathrm{N})$ and vaccination-protected mice $(\mathrm{V})$. a RNA was isolated from individual livers prepared on different days $(\mathrm{d} 0, \mathrm{~d} 1, \mathrm{~d} 4, \mathrm{~d} 8, \mathrm{~d} 11)$ during infection with P. chabaudi blood-stage malaria. Gene expression levels for the individual livers were determined by microarrays and hierarchically clustered. $\log _{2}$ transformed expression levels range from 0 to 18 as indicated at the top with blue (low expression) and red (high expression), respectively. $\mathbf{b}$ Hierarchical clustering of liver samples prepared from vaccination-protected $(V)$ and non-vaccinated mice $(N)$ during different phases of infections with P. chabaudi malaria on the indicated days (d0, d1, d4, d8, d1 1). Suffices indicate the three different livers taken per time point. The correlation metric and the average linkage method were used to construct the dendogram. c Principal Component Analysis (PCA) of gene expression data. The 1st principal component (PC1) captures $40 \%$ of the gene expression variability and the 2 nd PC2 captures $10 \%$ of the variability. The Nd0 populations are depicted by blue spheres, the Nd1 by cyan spheres, the $\mathrm{Nd} 4$ by green spheres, the $\mathrm{Nd} 8$ by magenta spheres, the $\mathrm{Nd} 11$ by red spheres, the $\mathrm{Vd} 0$ by blue icosahedra, the $\mathrm{Vd} 1$ by cyan icosahedra, the $\mathrm{Vd} 4$ by green icosahedra, the $\mathrm{Vd} 8$ by magenta icosahedra and the $\mathrm{Vd} 11$ by red icosahedra

those liver samples taken before day 8 p.i. (positive coordinates) and those taken after day 8 p.i. samples (negative coordinates).

Collectively, the global transcriptomics analysis results indicate (i) that constitutive expression of the vast majority of hepatic genes is not essentially changed by protective vaccination, (ii) that $P$. chabaudi infections induce changes in hepatic RNA expression, being usually highest at peak parasitaemia on day $8 p . i$. and towards the end of crisis on day 11 p.i., and (iii) that the malaria-induced changes in hepatic gene expression are modified by protective vaccination, particularly at early patency on day 4 p.i. and towards the end of crisis on day 11 p.i.

\section{Erythropoiesis-involved genes are expressed in the liver of non-infected mice}

The heatmap in Fig. 2 shows the expression profiles of the selected 23 genes known to encode important nonhaemoglobin constituents of erythrocytes and the EPO encoding gene known to stimulate erythropoiesis. The numbers in the heatmap indicate the probe-detected expression levels of genes which were $\log _{2}$ transformed 


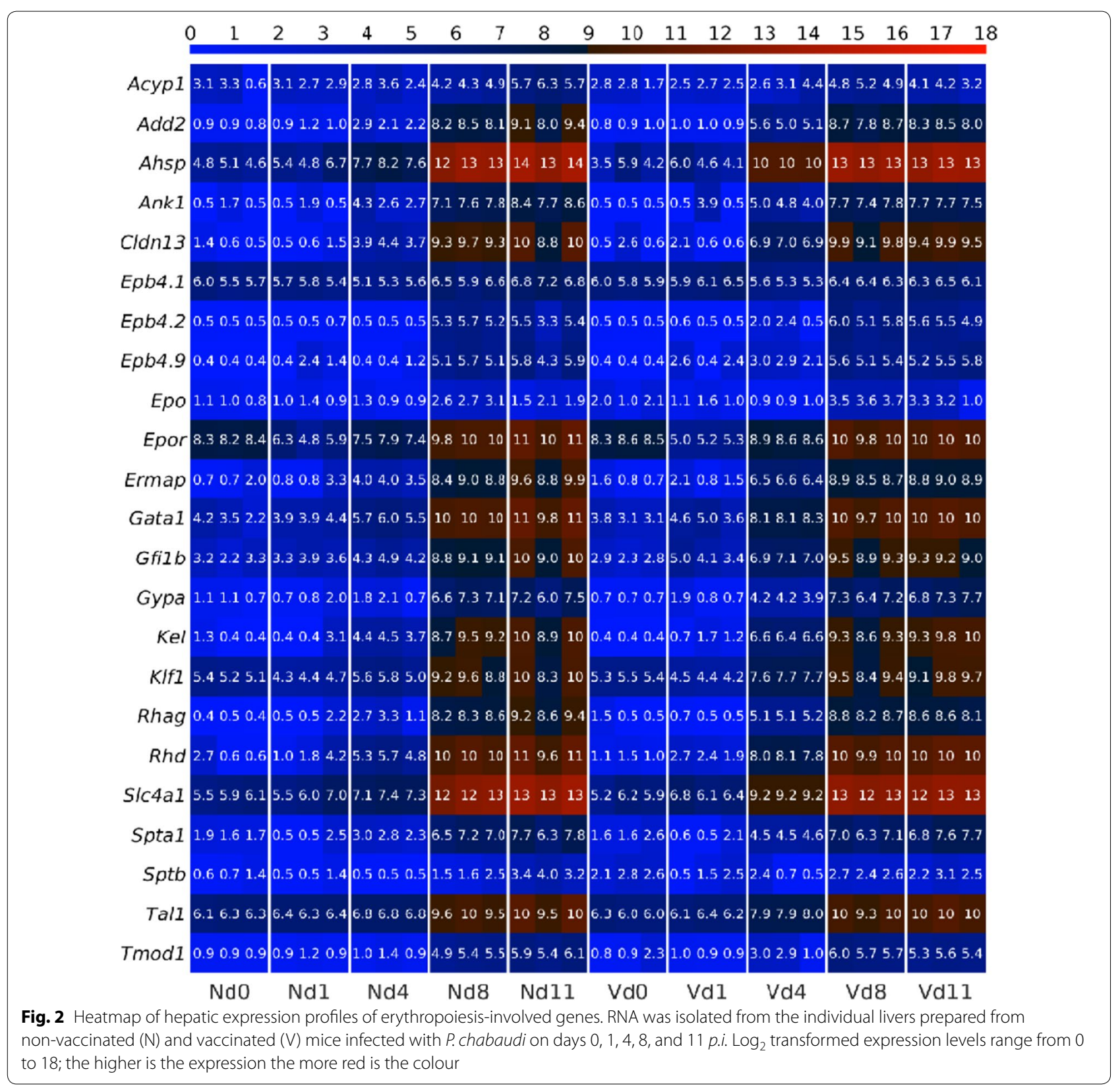

for variance stabilization. In the liver of non-vaccinated mice on day 0 p.i., the expression of a given gene is similar among the 3 microarrays prepared from the 3 mice (Nd0 in Fig. 2) and also with the corresponding probes on the microarrays of the 3 vaccinated mice on day 0 p.i. (Vd0 in Fig. 2). However, the 23 genes reveal varying constitutive expression levels, which, however, are approximately the same at both $\mathrm{Nd} 0$ and $\mathrm{Vd} 0$. For instance, low constitutive expression levels reveal the genes Epb4.2, Epb4.9, Rhag, Ermap, Spta, and Sptb at both Nd0 and Vd0, whereas higher expression levels are found for the genes Epor, Slc4a1, Gata1, Klf1, and Tal1 in both vaccinated and non-vaccinated mice (Fig. 2). This supports the view that constitutive expression of erythroid genes in non-infected mice is not essentially affected by vaccination.

\section{Erythroid genes respond to infections with increasing expressions in non-vaccinated mice}

The heatmap in Fig. 2 also shows that blood-stage infections of $P$. chabaudi malaria induce increasing expressions of the 23 erythroid genes in the liver, but with 
differences among vaccinated and non-vaccinated mice. To make these differences clearer and better comparable, the expression profiles were plotted in a linear scale as time series with the corresponding trajectories presented in Figs. 3, 4, 5, 6.

Blood-stage infections with $P$. chabaudi induce only a slight increase in the expression of all the 23 erythropoiesis-involved genes between days 0 p.i. and 4 p.i. Thereafter, an abrupt increase in expression is observed at peak parasitaemia on day 8 p.i., and the increase even continues reaching still higher mRNA expression levels towards the end of the crisis phase on day 11 p.i. Among genes encoding membrane-associated proteins $[45,46]$, the gene Slc4a1 coding for the major integral multi-pass membrane protein band 3 and the gene Gypa encoding the major one-pass membrane protein of the Gyp family reach maximal mRNA expression levels of approximately 180 and 50 above the normalization level, respectively (Fig. 3). The genes $\mathrm{Kel}$ and $R h d$ coding for blood groups and Rhag coding for the Rhblood group associated transmembrane glycoprotein reveal maximal expressions of approximately 100, 120, and 90, respectively, on day 11 p.i. (Fig. 3). Ermap known to encode a protein associated with the outer surface of erythroblasts displays maximal expression of approximately 90 on day 11 p.i. A very similar timecourse of expression with a maximum level of approximately 100 reveals Cldn13 (Fig. 3), whose encoded protein has been previously suggested to be associated with erythroblastic islands [35]. Lower maximal expressions on day 11 p.i. exhibit those genes, whose encoded proteins are known to be associated with the cytoskeletal meshwork on the inner surface of the erythrocyte plasma membrane (Fig. 4). Among them are Spta, Sptb, Epb4.1, Epb4.2, Epb4.9, and Tmod1 [45, 46], whose maximal expressed mRNA levels vary between 15 and 50 above the normalization level, respectively. Only the genes $A d d 2$ involved in the assembly of the spectrinactin cytoskeletal network and Ank1 involved in the linkage of integral membrane proteins to the underlying cytoskeletal meshwork display higher expression levels between 80 and 70, respectively (Fig. 4).

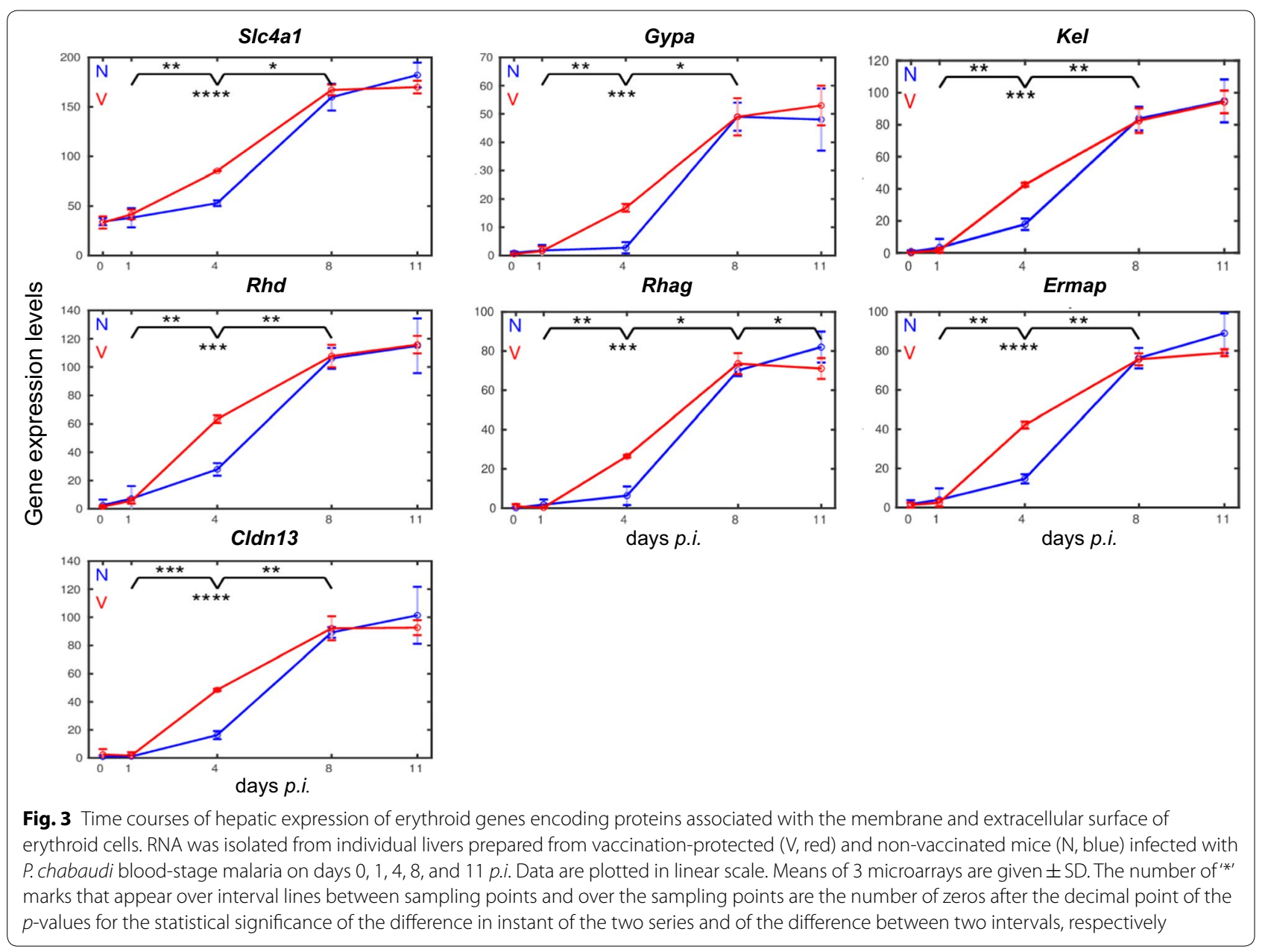




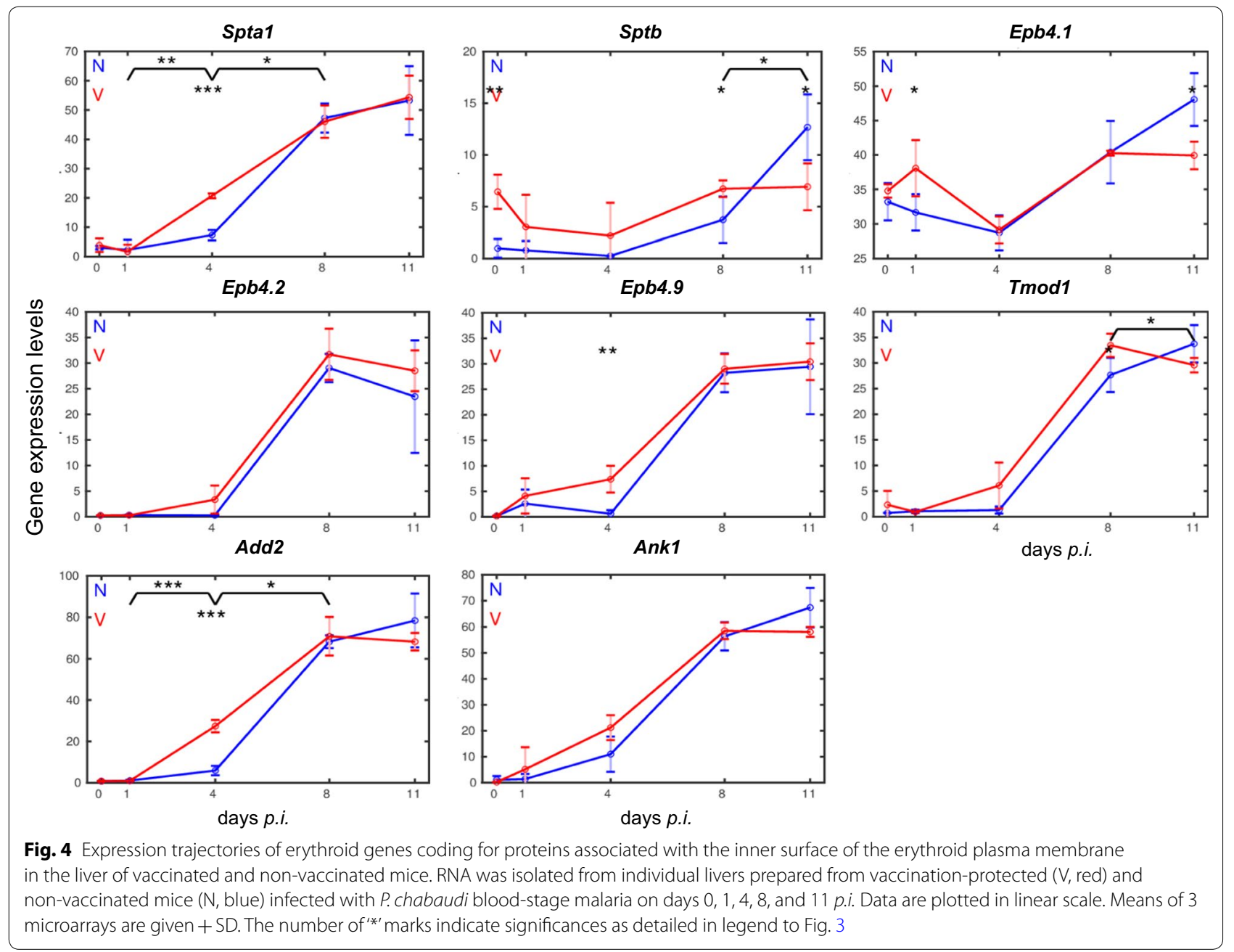

The genes Gata1, Gfilb, Klf1, and Tal1 encode transcription factors which are known to be critically involved in erythropoiesis [47-49]. These genes also reach high expressions between approximately 80 and 110 above the normalization level towards the end of the crisis phase (Fig. 5). Among all erythroid genes responding to malaria, Ahsp, encoding the $\alpha$ haemoglobin stabilizing protein, exhibit the highest mRNA expression of approximately 190 towards the end of the crisis phase (Fig. 5). However, a maximal expression level of only approximately 35 reveals the gene Acyp 1 encoding the erythrocytic acylphosphatase.

Erythropoiesis, in particular erythroblastosis, is critically dependent on EPO signaling through its receptor EPOR [23, 24]. Epor and Epo display a time-course of mRNA expression, which differs from that determined for the other erythroid genes in two aspects (Fig. 6). Epor reveals a sharp decline in its relative expression level from about 75 on day 0 p.i. to about 25 on day 1 p.i.., before it continuously increases almost linearly reaching its maximal level of about 120 towards the end of crisis on day 11 p.i. By contrast, Epo expression is impaired during the first 4 days of infection, then it sharply increases reaching its maximum expression of approximately 8 at peak parasitaemia on day 8 p.i., before declining to a level of about 3 towards the end of the crisis phase on day 11 p.i.

\section{Expression of erythroid genes is accelerated in the liver of vaccination-protected mice}

In contrast to un-protected non-vaccinated mice, the expression of the vast majority of erythroid genes in the liver of vaccination-protected mice is accelerated during infections, as evidenced by three facts. First, the erythroid genes are significantly much higher expressed at early patency on day $4 p . i$. than the corresponding genes in the liver of non-vaccinated mice (cf. Figs. 3, 4, 5, 6). This significant higher expression is confirmed when the corresponding genes are directly compared between vaccinated and non-vaccinated mice on day $4 p . i$. or when 

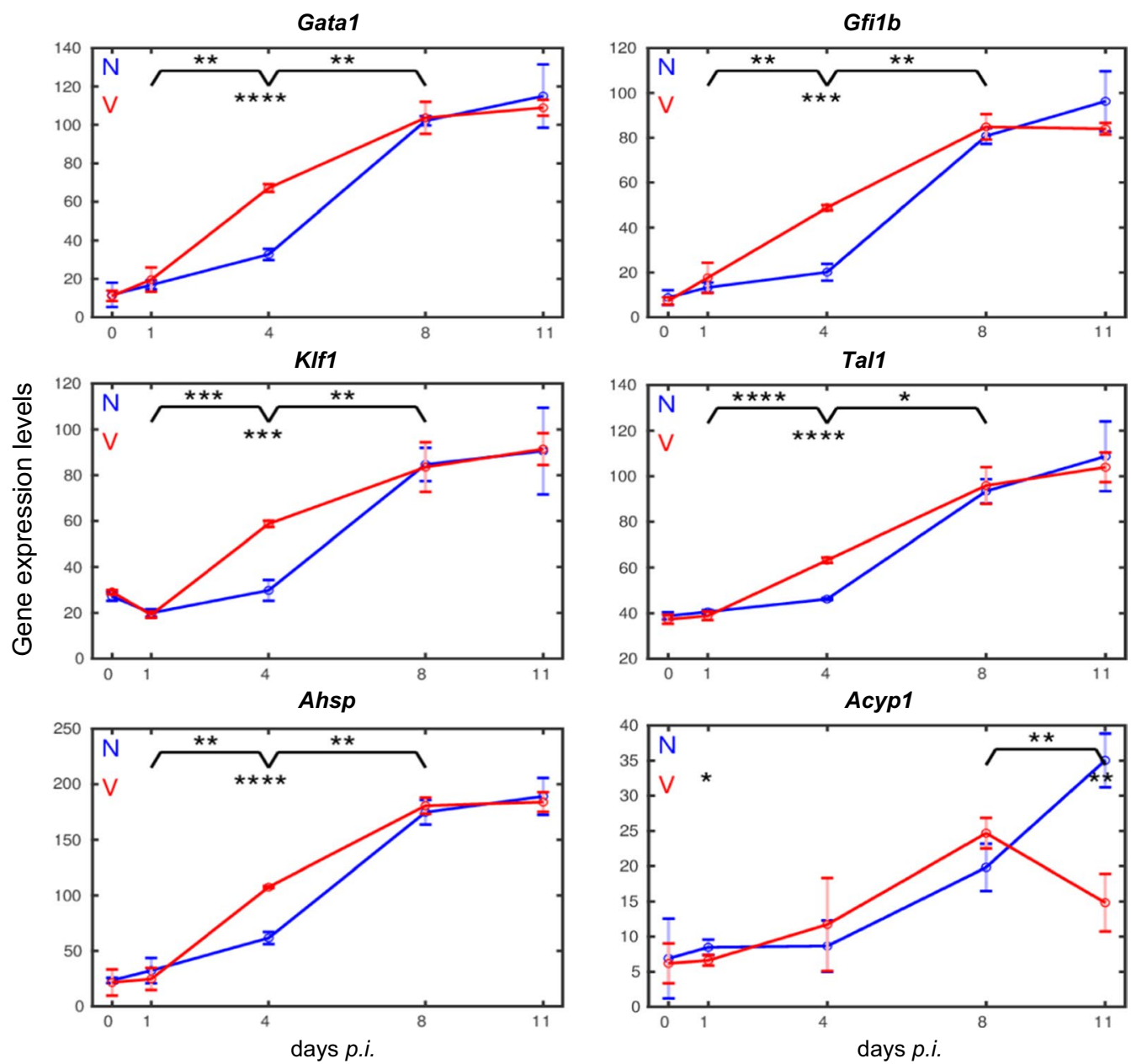

Fig. 5 Expression trajectories of genes encoding erythropoiesis-involved transcription factors and other internal erythroid proteins. RNA was isolated from individual livers prepared from vaccination-protected $(\mathrm{V}$, red) and non-vaccinated mice ( $\mathrm{N}$, blue) infected with P. chabaudi blood-stage malaria on days $0,1,4,8$, and 11 p.i. Data are plotted in linear scale. Means of 3 microarrays are given $\pm S D$. The number of ${ }^{\prime * \prime}$ marks indicate significances as detailed in legend to Fig. 3

the increases in expression levels between day 1 p.i. and day 4 p.i. is compared in vaccinated mice $v s$ nonvaccinated mice. The only exception is Epb4.1 (Fig. 4): its expression is significantly higher on day $1 p . i$. in vaccinated mice, then it decreases to approximately the same low level as that of non-vaccinated mice on day 4 p.i., before it increases again reaching maximal expression at peak parasitaemia on day 8 p.i., which is about the same as that towards the end of the crisis phase on day 11 p.i. Secondly, the majority of erythroid genes reach their maximal expression levels already at peak parasitaemia on day 8 p.i. and keep about the same level during crisis, in contrast to non-vaccinated mice in which the corresponding genes reach their maximal expression levels on day $11 p . i$. Thirdly, the final expression levels on day 11 p.i. are mostly lower with lower standard deviations in vaccination-protected mice than those of the corresponding genes in the liver of non-vaccinated unprotected mice (cf. Figs. 3, 4, 5, 6). A few genes in the liver of vaccinated mice, which still show a minor increase of mRNA expressions after peak parasitaemia on day 8 p.i., slow down their expressions towards the end of the crisis phase on day 11 p.i. Some genes, as e.g. Rhag, Epb4.1, Sptb, Tmod 1 and Acyp1, have even significantly declined their expression levels on day 11 p.i.

Remarkably, the time course of expression of Epor in the liver of vaccinated mice is very similar to that of other genes proceeding from a level of about 25 on day 1 p.i. and reaches maximal levels of almost 100 on days 8 and 11 p.i. (Fig. 6). Also, the increase in expression of Epor between day 1 p.i. and day 4 p.i. as well as the expression on day 4 p.i. is significantly higher in vaccinated mice than in non-vaccinated mice. Remarkably, the time course of Epor expression significantly differs to 

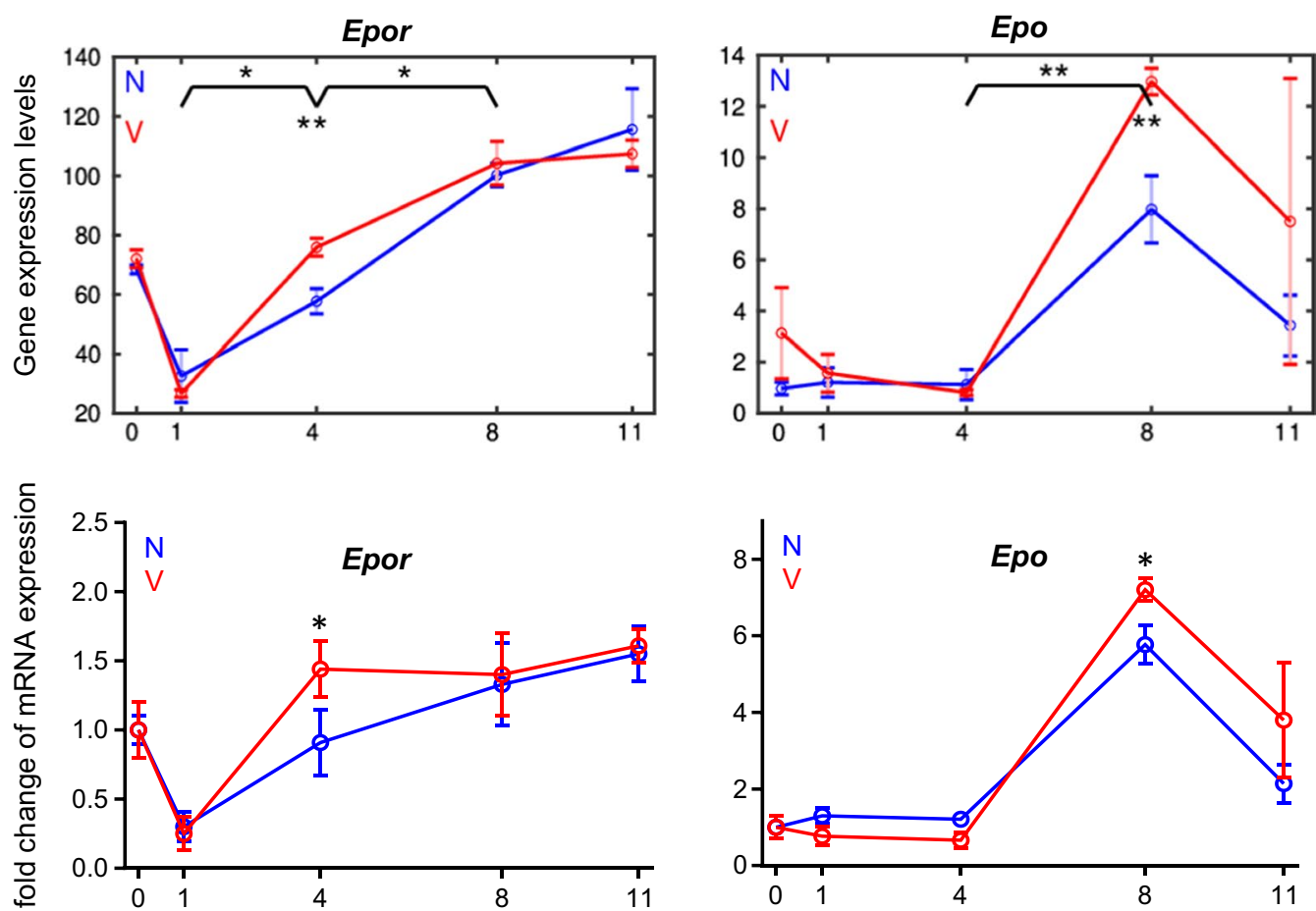

Fig. 6 Time course of expression of Epor and Epo in the liver of vaccination-protected and non-protected mice. RNA was isolated from individual livers prepared from vaccination-protected $(\mathrm{V}$, red) and non-vaccinated mice $(\mathrm{N}$, blue) infected with $\mathrm{P}$. chabaudi blood-stage malaria on days $0,1,4$, 8 , and 11 p.i. The upper curves show microarray data, the lower curves qPCR data. The number of ${ }^{\prime * \prime}$ marks in microarray data indicate significances as detailed in legend to Fig. 3. ${ }^{* \prime}$ in qPCR data indicate significant differences between vaccinated and non-vaccinated mice $(p<0.05)$

that of Epo. Indeed, Epo expression is delayed during the first 4 days of infections, i.e., Epo is expressed at approximately the same very low level between day 0 p.i. and 4 $p . i$. in vaccinated mice as in non-vaccinated mice. Moreover, the maximal levels of Epo expression at peak parasitaemia on day $8 p . i$. are significantly higher in the liver of vaccinated mice than in non-vaccinated mice (Fig. 6), though vaccination decreases maximum parasitaemia by approximately $30 \%$ in comparison with non-vaccinated mice $[8,43]$.

\section{Quantitative PCR validates the response of erythroid genes to infections}

Quantitative PCR (qPCR) was used to re-examine, in both non-vaccinated and vaccinated mice, the time courses of expression of some arbitrarily selected erythroid genes, whose expression was identified by microarrays to respond to $P$. chabaudi blood-stage malaria. The data are summarized in Fig. 7. The trajectories of Ermap expression in both vaccinated and non-vaccinated mice during infection take a similar course as those detected by the microarray probes (Fig. 3). Moreover, the qPCRdetermined trajectories for expression of Gata1, Add2, Slc4a1, Rhd, and Cldn13 take a similar course as those determined by microarrays (cf. Fig. 7 with Figs. 3, 4, 5). In particular, there a higher increase in expression was observed at early patency on day $4 p . i$. and a lower expression towards the end of the crisis phase on day $11 p . i$. in vaccinated mice than in non-vaccinated mice. Furthermore, correspondence largely exists between microarray and qPCR data with respect to the tendency of increasing expression for Epb4.2, Epb4.9, and Acyp1 (Fig. 7). Similarly to microarray data, the 9 genes examined by qPCR reveal maximal expression levels in the liver of vaccinated mice at peak parasitaemia on day $8 p . i$., whereas, in the liver of non-vaccinated mice, maximal expression of the majority of these genes is reached towards the end of crisis phase on day 11 p.i. Furthermore, the expressions of Epor and Epo measured by qPCR take very similar courses in vaccinated and non-vaccinated mice as those determined by microarrays (Fig. 6).

\section{Discussion}

This study provides evidence that vaccination, using a non-infectious vaccine consisting of erythrocyte ghosts isolated from $P$. chabaudi-infected erythrocytes, accelerates expression of erythroid genes in the liver induced by blood-stage malaria of $P$. chabaudi. Indeed, these genes 


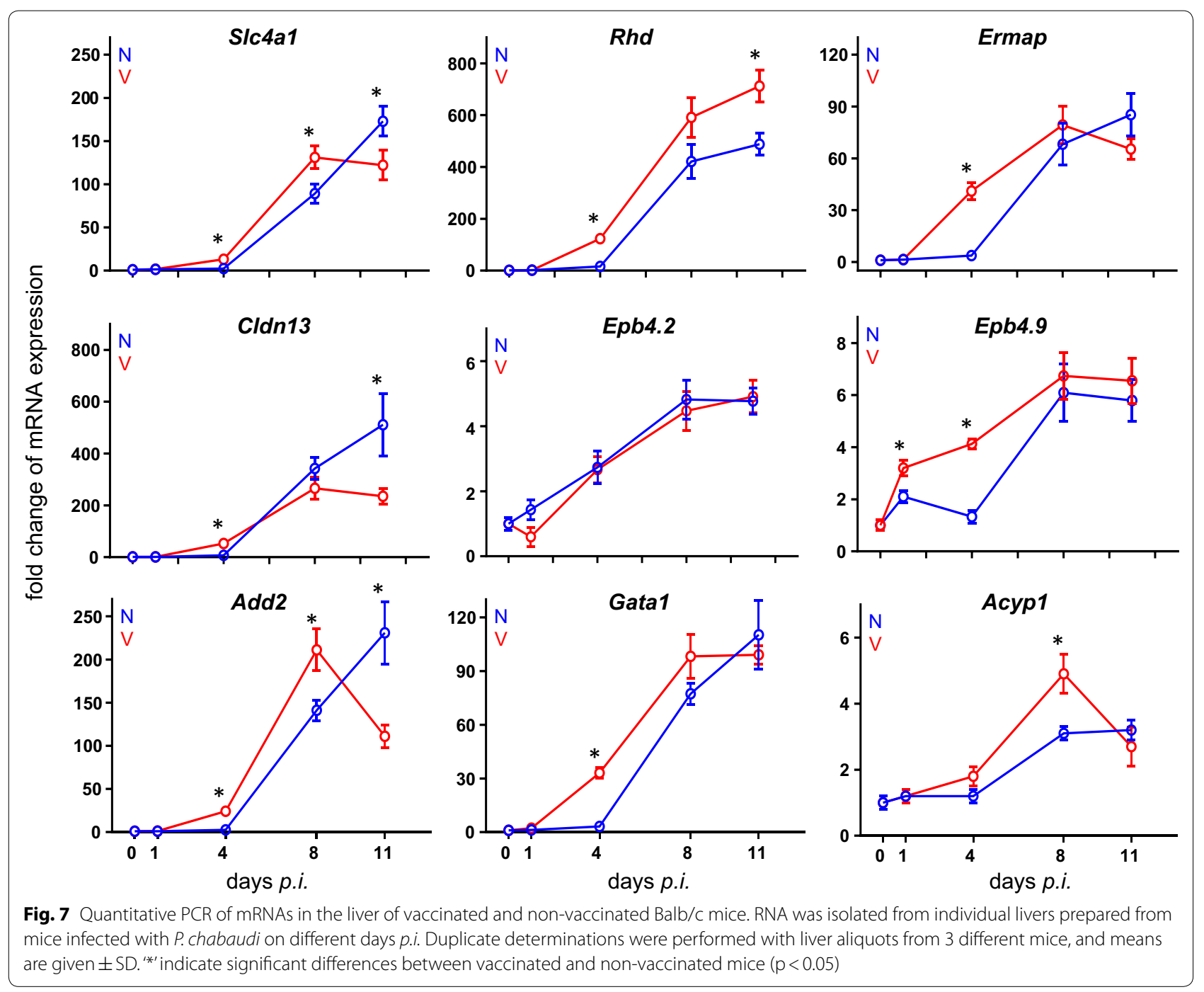

encompass Slc4a1 and Gypa encoding band 3 and Glycophorin A, major integral membrane proteins of red blood cells; Rhd, Kel and Rhag coding for blood group antigens and $\mathrm{Rh}$-associated antigen glycoprotein exposed on the outer membrane surface of red blood cells; Ermap and $C l d n 1$ encoding presumably proteins associated with the outer surface of erythroblasts [25]; $A d d 2$ and Ank1 coding for proteins linking integral membrane proteins with peripheral skeletal proteins located on the inner surface of erythroid cells, as e.g., Epb4.2, Epb4.9, Spta, and Sptb [45, 46]; Acyp1 and Ahsp encoding proteins within erythroid cells; and even Gata1, Gfilb, Tal1 and Klf1 coding for transcription factors critically involved in erythropoiesis [47-49]. Expression of these genes takes an accelerated time-course in surviving vaccinated mice, evidenced as it is significantly higher at early patency on day $4 p . i$. and as it is often more slowed down or even lower towards the end of the crisis phase on day $11 p . i$. than those expression time-courses taken by the corresponding genes during lethal infections in non-vaccinated mice. Thus, the results indicate that the liver responds to blood-stage malaria with extramedullary erythropoiesis, especially erythroblastosis in the liver, and erythroblastosis is obviously accelerated by vaccination.

Erythroblastosis is critically dependent on the interplay of EPO and EPOR, respectively [23, 24]. In accordance, extramedullary erythroblasts in the liver apparently display EPO sensitivity, evidenced as Epor expression taking approximately the same time-course as that taken by the other erythroid genes in vaccination-protected mice. Moreover, it is remarkable that Epo expression also occurs in the liver during extramedullary erythroblastosis. Indeed, there is evidence that EPO is not only produced by kidneys, but also by other cells including hepatocytes [23, 50]. In contrast to Epor and the other 
examined erythroid genes, however, hepatic expression of Epo is not accelerated during extramedullary erythroblastosis, rather it is delayed at least for the first 4 days of infections. Maximal Epo expression is reached at peak parasitaemia on day 8 p.i. both in vaccinated and nonvaccinated mice, but is much higher in vaccinated mice than in non-vaccinated mice, though, incidentally, nonvaccinated mice exhibit a higher peak parasitaemia by about $30 \%$ than vaccination-protected mice. The data, therefore, suggest that EPOR-mediated EPO sensitivity by hepatic erythroblasts precedes EPO production in the liver, and that malaria-induced erythroblastosis in the liver may require hepatic EPO particularly at peak parasitaemia. However, it cannot be excluded that hepatic EPO may be also involved in the stimulation of other processes in the liver, which are important to survive blood-stage malaria. For instance, EPO has been recently described to recruit Ly6C ${ }^{\text {hi }}$ monocytes in response to liver injury [51] and to stimulate proliferation and phagocytotic activity of Kupffer cells-the liver-resident macrophages known for its capacity of erythrophagocytosing Plasmodiumparasitized red blood cells [11, 12, 14-16]. Liver injury does also occur during blood-stage malaria in mice and even humans $[11,52]$. Moreover, EPO has been reported to inhibit inflammation and gluconeogenesis in the liver [53]. Attenuated inflammation of the liver and decreased glucose blood levels after crisis was also found in vaccination-protected mice infected with $P$. chabaudi $[8,11]$.

Extramedullary erythroblastosis in the liver of vaccination-protected mice may be reasonably assumed to contribute to overcome malaria-induced anemia and replenishment of peripheral erythrocytes, whose number is increasingly declining with progressing $P$. chabaudi blood-stage infections. This view is supported by previous results obtained under identical experimental conditions as used here [8]. Indeed, P. chabaudi-parasitized erythrocytes begin to appear in peripheral blood of both vaccinated and non-vaccinated mice on day 4 p.i., and peripheral red blood cells in both vaccinated and nonvaccinated mice begin to decrease after day 5 p.i., i.e., from approximately $9 \times 10^{6} / \mu \mathrm{l}$ on day $5 \mathrm{p} . i$. to approximately $5.5 \times 10^{6} / \mu \mathrm{l}$ on day $6 \mathrm{p} . i$. The lowest levels of approximately $1.8 \times 10^{6} / \mu \mathrm{l}$ peripheral red blood cells were reached at peak parasitaemia on day 8 p.i. [8]. This very low level of peripheral erythrocytes remains in nonvaccinated mice until deceasing at latest at the end of the crisis phase on approximately day $11 p . i$., though there is observable a slight increase of peripheral reticulocytes at that time. In vaccinated mice, however, the increase in peripheral reticulocytes is accelerated and already begins about 1-2 days earlier than in non-vaccinated mice reaching higher levels at the end of crisis on day $11 \mathrm{p} . i$. [8]. This earlier appearance of peripheral reticulocytes may be due to an accelerated terminal erythroid differentiation in vaccination-protected mice, i.e., final denucleation of erythroblasts and release of denucleated reticulocytes into liver sinusoids and blood vessels, respectively, begin 1-2 days earlier in vaccination-protected mice than in unprotected non-vaccinated mice.

The accelerated extramedullary erythropoiesis in the liver of vaccination-protected mice may be also viewed as an important contribution of the liver to the host defense system against blood-stage malaria. At the end of crisis on day 11 p.i., for example, when parasitaemia has dramatically declined to about $1-5 \%$ in both vaccinated and non-vaccinated mice, there is accumulated a large excess of peripheral reticulocytes, representing approximately $90 \%$ of all peripheral red blood cells, only in vaccination protected mice [8]. This suggests that, at least at that time-point, vaccinated mice are less vulnerable to blood-stage infections, since reticulocytes-in contrast to erythrocytes-are not preferred as host cells by $P$. chabaudi [54]. A major reason for the host cell specificity of $P$. chabaudi for erythrocytes may be that reticulocytes differ from erythrocytes with respect to composition, organization and properties of their plasma membranes $[45,46]$. Even erythrocytes during their aging are subjected to modifications in membrane components. For instance, there is evidence for an increase in the ratio of band 4.1a:4.1b during erythrocyte aging [55]. These hub proteins are not only involved in the organizational cross-linking of the spectrin network to the inner surface of red cell plasma membranes [56], but also favour the formation of elliptotic red cells, which are known to hinder red cell invasion by Plasmodium parasites [57, 58]. In accordance, there has been previously described a decrease of band $4.1 \mathrm{a}$ in erythrocytes of C57BL/10 mice after survival of $P$. chabaudi blood-stage infections [59]. Remarkably, the present study shows that the time course of Epb4.1 expression differs from that of all the other examined erythroid genes insofar as there is dramatic decline on day 4 p.i., when all other erythroid genes reveal an increased expression. Furthermore, there is ample evidence for other abnormalities, deficiencies and/or mutations of erythrocytes in their membrane or internal constituents which restrict invasion and/or internal survival of malaria parasites, respectively [60, 61]. It is therefore attractive to speculate that the accelerated extramedullary erythroblastosis in the liver of vaccination-protected mice ultimately leads, by the end of crisis phase, to an earlier transient excess of peripheral reticulocytes, being unfavourable for parasite survival, thus resulting in a dramatic decline of potential erythrocyte host cells for $P$. chabaudi parasites. This temporary impairment of parasite multiplication may concomitantly allow the evolvement of immune mechanisms 
finally contributing to resolve blood-stage infections of $P$. chabaudi.

\section{Conclusion}

This study indicates that vaccination accelerates extramedullary erythroblastosis, induced in the liver by blood-stage malaria of $P$. chabaudi, for 1-2 days. This presumably contributes to earlier replenishment of peripheral red blood cells by liver-derived reticulocytes. This in turn is speculated to favour final survival of otherwise lethal blood-stage malaria, since reticulocytes - in contrast to mature erythrocytes-are known to be not preferred as host cells by $P$. chabaudi.

\begin{abstract}
Abbreviations
ACYP1: acylphosphatase 1 erythrocyte isozyme; ADD2: adducin2; AHSP: a haemoglobin stabilizing protein; ANK1: ankyrin 1; CLDN13: claudin13; CFU-e: colony-forming unit-erythroid; EPB4.1: Erythrocyte membrane protein band 4.1; EPB4.2: Erythrocyte membrane protein 4.2; EPB4.9: Erythrocyte membrane protein 4.9; EPO: erythropoietin; EPOR: erythropoietin receptor; ERMAP: erythroblast membrane associated protein; FCA: Freund's complete adjuvant; GAPDH: glycerinaldehyd-3-phosphat-Dehydrogenase; GATA1: GATA-binding factor 1; GFI1B: growth factor independent 1B transcriptional repressor; GYPA: glycophorin A; KEL: Kell blood group antigen; KLF1: Krueppel-like factor 1; PCA: principal component analysis; RHAG: Rh-associated glycoprotein; RHD: Rh blood group D antigen; SLC4A1: solute carrier family 4 member 1; SPTA1: spectrin a erythrocytic 1; SPTB: spectrin $\beta$ erythrocytic; TAL 1:T cell acute lymphocytic leukemia protein 1;TMOD1: tropomodulin 1.
\end{abstract}

\section{Acknowledgements}

Not applicable.

\section{Authors' contributions}

SA, MAD and FW designed the study; MAD, ASA, MJA, and DD carried out the experiments and analysed the data. All authors wrote and revised the manuscript. All authors read and approved the final manuscript.

\section{Funding}

This project was funded by the National Plan for Science, Technology and Innovation (MAARIFAH), King Abdulaziz City of Science and Technology, and Kingdom of Saudi Arabia, Award Number (13-B101206-02).

\section{Availability of data and materials}

The datasets used and/or analysed during the current study are available from the corresponding author on reasonable request. The microarray data have been deposited at the NCBI's Gene Expression Omnibus (GEO) database with accession number GSE129133.

\section{Ethics approval and consent to participate}

This study was carried out in strict accordance with the German law on animal protection. The maintenance of mice as well as the experimental protocol of the study were officially approved by the State-controlled Committee on the Ethics of Animal Experiments of the State Northrhine-Westphalia, Germany, and were regularly monitored without prior notice by the local authorities. All efforts were undertaken to minimize the suffering of mice.

\section{Consent for publication}

Not applicable.

\section{Competing interests}

Author Denis Delić was employed by company Boehringer Pharma GmbH \& Co. KG, Ingelheim, Biberach, Germany. All other authors declare no competing interests.

\section{Author details}

${ }^{1}$ Department of Biology, Heinrich-Heine-University, Duesseldorf, Germany. 2 Boehringer Ingelheim Pharma, Biberach, Germany. ${ }^{3}$ Department of Zoology, College of Science, King Saud University, Riyadh, Saudi Arabia. ${ }^{4}$ Department of Zoology, Faculty of Science, Beni-Suef University, Beni Suef, Egypt. ${ }^{5}$ Department of Zoology and Entomology, Faculty of Science, Helwan University, Cairo, Egypt. ${ }^{6}$ Group of Computational Biology and Systems Biomedicine, Biodonostia Health Research Institute, San Sebastián, Spain. ${ }^{7}$ Ikerbasque, Basque Foundation for Science, Bilbao, Spain.

Received: 20 November 2019 Accepted: 18 January 2020

Published online: 29 January 2020

\section{References}

1. WHO. World malaria report 2018. Geneva: World Health Organization; 2018.

2. Gosling R, von Seidlein L. The future of the RTS, S/AS01 malaria vaccine. an alternative development plan. PLoS Med. 2016;13:e1001994.

3. Ashley EA, Pyae Phyo A, Woodrow CJ. Malaria. Lancet. 2018;391:1608-21.

4. Draper SJ, Sack BK, Richter King C, Nielsen CN, Rayner JC, Higgins MK, et al. Malaria vaccines: recent advances and new horizons. Cell Host Microbe. 2018;24:43-56.

5. Longley R, Smith C, Fortin A, Berghout J, McMorran B, Burgio G, et al. Host resistance to malaria: using mouse models to explore the host response. Mamm Genome. 2011:22:32-42.

6. Stephens R, Culleton RL, Lamb TJ. The contribution of Plasmodium chabaudi to our understanding of malaria. Trends Parasitol. 2012;28:73-82

7. Wunderlich F, Brenner H, Helwig M. Plasmodium chabaudi malaria: protective immunization with surface membranes of erythrocytes infected with Plasmodium chabaudi. Infect Immun. 1988;56:3326-8.

8. Krücken J, Delic D, Pauen H, Wojtalla A, El-Khadragy M, Dkhil MA, et al. Augmented particle trapping and attenuated inflammation in the liver by protective vaccination against Plasmodium chabaudi malaria. Malar J. 2009;8:54.

9. Del Portillo HA, Ferrer M, Brugat T, Martin-Jaular L, Langhorne J, Lacerda MVG. The role of the spleen in malaria. Cell Microbiol. 2012;14:343-55.

10. White NJ. Malaria parasite clearence. Malar J. 2017;16:88.

11. Wunderlich F, Al-Quraishy S, Dkhil M. Liver-inherent immune system: its role in blood-stage malaria. Front Microbiol. 2014:5:559.

12. Terpstra V, Berkel TJ. Scavenger receptors on liver Kupffer cells mediate the in vitro uptake of oxidatively damaged red blood cells in mice. Blood. 2000;15:2157-63.

13. Krücken J, Mehnert LI, Pauen H, Woijtalla A, El-Khadragy M. Massive destruction of malaria-parasitized red blood cells despite spleen closure. Infect Immun. 2005;73:6390-8.

14. Delic D, Warskulat U, Borsch E, Al-Qahtani S, Al-Guraishy S, Häussinger D, et al. Loss of ability to self-heal malaria upon taurine transporter deletion. Infect Immun. 2010;78:1642-9.

15. Lee SJ, Park SY, Jung MY, Bae SM, Kim IS. Mechanism for phosphatidylserine-dependent erythrophagocytosis in mouse liver. Blood. 2011;117:5215-23.

16. Theurl I, Hilgendorf I, Nairz N, Tymoszuk P, Haschka D, Asshoff M, et al. On-demand erythrocyte disposal and iron recycling requires transient macrophages in the liver. Nat Med. 2016;22:945-51.

17. Dzierzak E, Philipsen S. Erythropoiesis: development and differentiation. Cold Spring Harb Perspect Med. 2013;3:a011601.

18. An X, Schulz VP, Mohandas N, Gallagher PG. Human and murine erythropoiesis. Curr Opin Hematol. 2015;22:206-11.

19. Zivot A, Lipton JM, Naria A, Blanc L. Erythropoiesis: insights into pathophysiology and treatments in 2017. Mol Med. 2017;24:11.

20. Klei TRL, Meinderts SM, van den Berg TK, van Bruggen A. From the cradle to the grave: the role of macrophages in erythropoiesis and erythrophagocytosis. Front Immunol. 2017;8:73.

21. Seu KG, Papoin J, Fessler R, Horn J, Huang G, Mohandas N, et al. Unraveling macrophage heterogeneity in erythroblastic islands. Front Immunol. 2017;8:1140. 
22. Moras M, Lefevre SD, Ostuni MA. From Erythroblasts to mature red blood cells: organelle clearance in mammals. Front Physiol. 2017;8:1076.

23. Elliott S, Sinclair AM. The effect of erythropoietin on normal and neoplastic cells. Biologics. 2012;6:163-89.

24. Wang J, Hayashi Y, Yokota A, Xu Z, Zhang Y, Huang R, et al. Expansion of EPOR-negative macrohpages besides erythroblasts by elevated EPOR signaling in erythrocytosis mouse models. Haematologica. 2018;103:40-50.

25. Chang KH, Stevenson MM. Malarial anaemia: mechanisms and implications of insufficient erythropoiesis during blood-stage malaria. Int J Parasitol. 2004;34:1501-16.

26. Chang KH, Tam M, Stevenson MM. Modulation of the course and outcome of blood-stage malaria by erythropoietin-induced reticulocytosis. J Infect Dis. 2004;189:735-43.

27. Thawani N, Tam M, Bellemare MJ, Bohle DS, Olivier M, de Souza JB, et al. Plasmodium products contribute to severe malarial anemia by inhibiting erythropoietin-induced proliferation of erythroid precursors. J Infect Dis. 2014;209:140-9.

28. Li LX, Benoun JM, Weiskopf K, Garcia KC, McSorley SJ. Salmonella infection enhances erythropoietin production by the kidney and liver, which correlates with elevated bacterial burden. Infect Immun. 2016;84:2833-41.

29. Otsuka H, Takito J, Endo Y, Yagi H, Soeta H, Yanagisawa N, et al. The expression of embryonic globin mRNA in a severely anemic mouse model induced by treament with nitrogen-containing bisphosphonate. Hematology. 2016;16:4

30. Alamo IG, Kannan KG, Loftus TJ, Ramos H, Efron PA, Mohr AM. Severe trauma and chronic stress activates extramedullary erythropoiesis. J Trauma Acute Care Surg. 2017;83:144-50.

31. Myllimäki MN, Määttä J, Dimova EY, Izzi V, Väisänen T, Myllyharju J, et al. Notch downregulation and extramedullary erythropoiesis in hypoxia inducible factor prolyl 4-hydroxylase 2-deficient mice. Mol Cell Biol. 2017;37:e00529.

32. Yap GS, Stevenson MM. Plasmodium chabaudi AS: erythropoietic responses during infection in resistant and susceptible mice. Exp Parasitol. 1992; $75: 340-52$

33. Abo T, Sekikawa H. Extrathymic T cells in malaria protection, including evidence for the onset of erythropoiesis in the liver during infection. Arch Histol Cytol. 2002;65:127-32

34. Halder RC, Abe T, Mannoor MK, Morshed SR, Ariyasinghe A, Watanabe $\mathrm{H}$, et al. Onset of hepatic erythropoiesis after malarial infection in mice. Parasitol Int. 2003;52:259-68.

35. Al-Quraishy SA, Dkhil MA, Abdel-Baki AA, Delic D, Wunderlich F. Protective vaccination against blood-stage malaria of Plasmodium chabaudi: differential gene expression in the liver of Balb/c mice toward the end of crisis phase. Front Microbiol. 2016;7:1087.

36. Al-Quraishy S, Dkhil MA, Al-Shaebi EM, Abdel-Baki AS, Araúzo-Bravo MJ, Delic $D$, et al. Gene expression of the liver of vaccine-protected mice in response to early patent infections of Plasmodium chabaudi blood-stage malaria. Malar J. 2018;17:215.

37. Wunderlich F, Helwig M, Schillinger G, Vial H, Philippot J, Speth V. Isolation and characterization of parasites and host cell ghosts from erythrocytes infected with Plasmodium chabaudi. Mol Biochem Parasitol. 1987;23:103-15.

38. Wunderlich F, Helwig M, Schillinger G, Speth V. Cryptic disposition of antigenic parasite proteins in plasma membranes of erythrocytes infected with Plasmodium chabaudi. Mol Biochem Parasitol. 1988;30:55-65.

39. Wunderlich F, Helwig M, Schillinger G, Speth V, Wiser MF. Expression of the parasite protein Pc90 in plasma membranes of erythrocytes infected with Plasmodium chabaudi. Eur J Cell Biol. 1988;47:157-64.

40. Wunderlich F, Stuebig H, Koenigk E. Development of Plasmodium chabaudi in mouse red blood cells: structural properties of the host and parasite membranes. J Protozool. 1982;29:60-6.

41. Wunderlich F, Dkhil M, Mehnert L, Braun J, El-Khadragy M, Borsch E, et al. Testosterone responsiveness of spleen and liver in female lymphotoxin beta receptor-deficient mice resistant to blood-stage malaria. Microbes Infect. 2005:7:399-409.
42. Wunderlich F, Mossmann H, Helwig M, Schillinger G. Resistance to Plasmodium chabaudi in B10 mice: influence of the $\mathrm{H}-2$ complex and testosterone. Infect Immun. 1988;56:2400-6.

43. Dkhil MA, Al-Quraishy SA, Abdel-Baki AS, Delic D, Wunderlich F. Differential miRNA expression in the liver of Balb/c mice protected by vaccination during crisis of Plasmodium chabaudi blood-stage malaria. Front Microbiol. 2017;7:2155.

44. Livak KJ, Schmittgen TD. Analysis of relative gene expression data using real-time quantitative PCR and the 2(-Delta Delta C(T)) method. Methods. 2002;25:402-8

45. Liu J, Guo X, Mohandas N, Chasis JA, An X. Membrane remodeling during reticulocyte maturation. Blood. 2010;8:241182.

46. Lux SE 4th. Anatomy of the red cell membrane skeleton: unanswered questions. Blood. 2016;127:187-99.

47. Love PE, Warzecha C, Li L. Lbd1 complexes: the new master regulators of erythroid gene transcription. Trends Genet. 2014;30:1-9.

48. Vassen L, Beauchemin H, Lemsaddek W, Krongold J, Trudel M, Moroy T. Growth factor independence $1 \mathrm{~b}$ ( $g$ fil $1 \mathrm{~b}$ ) is important for the maturation of erythroid cells and the regulation of embryonic globin expression. PLOS ONE. 2014:9:e96636.

49. Barbarani G, Fugazza C, Strouboulis J, Ronchi AE. The pleiotropic effects of GATA1 and KLF1 in physiological erythropoiesis and in dyserythropoietic disorders. Front Physiol. 2019;10:91.

50. Pinto JP, Ribeiro S, Pontes H, Thowfeequ S, Tosh D, Caevalho F, et al. Erythropoietin mediates hepcidin expression in hepatocytes through EPOR signaling and regulation of C/EBPalpha. Blood. 2008;2008(111):5727-33.

51. Gilboa D, Haim-Ohana Y, Deshet-Unger N, Ben-Califa N, Hiram-Bab S, Reuveni $D$, et al. Erythropoietin enhances Kupffer cell number and activity in the challenged liver. Sci Rep. 2017;7:10379.

52. Rupani AB, Amarapurkar AD. Hepatic changes in fatal malaria: an emerging problem. Ann Trop Med Parasitol. 2009;103:119-27.

53. Meng R, Zhu D, Bi Y, Yang D, Wang Y. Erythropoietin inhibits gluconeogenesis and inflammation in the liver and improves glucose tolerance in high-fat diet-fed mice. PLoS ONE. 2013;8:e53557.

54. Ott KJ. Influence of reticulocytosis on the course of infection of Plasmodium chabaudi and P. berghei. J Eukaryot Microbiol. 1968;15:365-9.

55. Mueller TJ, Jackson CW, Dockter ME, Morrison M. Membrane skeletal alterations during in vivo mouse red cell aging -increase in the band4.1a:4.1b ratio. J Clin Invest. 1987;79:492-9.

56. Baines AJ, Lu HC, Bennet PM. The protein 4.1 family: hub proteins in animals for organizing membrane proteins. Biochim Biophys Acta. 2014;1838:605-19.

57. Conboy JG, Chasis JA, Winardi R, Tchernia G, Kan YW, Mohandas N. An isoform-specific mutation in the protein 4.1 gene results in hereditary elliptocytosis and complete deficiency of protein 4.1 in erythrocytes but not in nonerythroid cells. J Clin Invest. 1993;91:77-82.

58. Chishti AH, Palek J, Fisher D, Maalouf GJ, Liu SC. Reduced invasion and growth of Plasmodium falciparum into elliptocytic red blood cells with a combined deficiency of protein 4.1, glycophorin C, and p55. Blood. 1996;87:3462-9.

59. Wunderlich F, Helwig M. Plasmodium chabaudi malaria: red blood cells with altered membrane proteins in immune mice. Eur J Cell Biol. 1987:43:499-500.

60. Lelliot PM, McMorran BJ, Foote SJ, Burgio G. The influence of host genetics on erythrocytes and malaria infection: is there therapeutic potential? Malar J. 2015;14:289.

61. Andolfo I, Russo R, Gambale A, Iolascon A. New insights on hereditary erythrocyte membrane defects. Haematol. 2016;101:1284-94.

\section{Publisher's Note}

Springer Nature remains neutral with regard to jurisdictional claims in published maps and institutional affiliations. 